УДК 340.12

DOI dx.doi.org/10.24866/1997-2857/2017-2/109-117

\author{
М.А. Дидык, А.Н. Ерыгин* \\ ФИЛОСОФИЯ ПРАВА Б.Н. ЧИЧЕРИНА \\ В ИСТОРИЧЕСКОМ КОНТЕКСТЕ
}

\begin{abstract}
Философия права Чичерина неплохо представлена в литературе, но аспект ее восприятия в историческом контексте (в связи с Гегелем) допускает новые идеи и наблюдения по следующим пунктам: взгляд на всемирную историю государства и права; концептуальная апелляция русского философа к «Философии истории» (феномен права и ось истории в римском мире, тема гражданского общества в средние века) и к «Феноменологии духа» (идея «отчужденного духа» в цивилизационной периодизации истории государства и права). В качестве источника авторы привлекают «Дневник» Чичерина.
\end{abstract}

Ключевые слова: философия права, Гегель, Чичерин, гражданское общество, отчужденный дух, «образованность», основной исторический закон

Chicherin's philosophy of law in historical context. MARINA A. DIDYK, ALEKSANDR N. ERYGIN (Southern Federal University)

Chicherin's philosophy of law is well represented in the literature. But the aspect of its perception in the historical context - in connection with Hegel's works -admits new ideas and observations on the following points: a glance at the world history of state and law; the conceptual appeal of the Russian philosopher to the "Philosophy of history" (the phenomenon of law and the axis of history in the Roman world, the theme of civil society in the Middle Ages) and the "The phenomenology of spirit" (the idea of an "alienated spirit" in the civilizational periodization of the history of state and law).

Keywords: philosophy of law, Hegel, Chicherin, civil society, alienated spirit, education, basic historical law

\section{К постановке проблемы}

В предлагаемой статье философия права Чичерина будет рассмотрена со стороны исторического аспекта: как философия всемирной истории государства и права и, с другой стороны, в связи с некоторыми важными идеями «Философии права» Гегеля. При этом мы попытаемся зафиксировать ключевую концептуаль- ную апелляцию Б.Н. Чичерина и к «Философии истории» Гегеля (подробнее об этом см.: [5]), и к его «Феноменологии духа» (подробнее об этом см.: [8; 10, с. 100-137]). Источниковой основой намечаемой реконструкции выступят не только главные произведения Б.Н. Чичерина, но и некоторые рукописные материалы из архива (Чичерин Б.Н. Дневник, 27 апреля - 21 ок-

* ДИДЫК Марина Александровна, кандидат философских наук, заведующий кафедрой истории русской философии и теоретического россиеведения Института философии и социально-политических наук Южного федерального университета.

E-mail: madidyk@yandex.ru

ЕРЫГИН Александр Николаевич, доктор философских наук, профессор кафедры истории русской философии и теоретического россиеведения Института философии и социально-политических наук Южного федерального университета.

E-mail: aerygin@philos.sfedu.ru

(C) Дидык М.А., Ерыгин А.Н., 2017 
тября 1851 г.; 14 апреля - лето 1856 г. Отдел рукописей Российской государственной библиотеки, далее - ОР РГБ. Ф. 334. К. 17. Ед. хр. 5; Чичерин Б.Н. Вставки для 2-го издания: «Наука и религия». ОР РГБ. Ф. 334. К. 31. Ед. хр. 2; Чичерин Б.Н. Диалектика. ОР РГБ. Ф. 334. К. 33. Ед. хр. 3).

Можно сказать, что интересующему нас вопросу в историографическом отношении уделяется определенное внимание. Общее проникновение в существо мировоззрения и философских ориентаций Чичерина обнаруживают в рамках классической историографии истории русской философии В.В. Зеньковский и Н.О. Лосский ${ }^{1}$; в сходной тональности рассматривается проблема «русского гегельянства» в классических работах по теме Б.В. Яковенко и Д. Чижевского ${ }^{2}$.

В обобщающих зарубежных трудах - в работе «Развитие историографии» [16, рр. 351-354], в книге А. Мазура «Очерк современной русской историографии» [19, pp. VII-IX, 98-112]- отмечено влияние Гегеля на Чичерина. В монографии К.-Д. Гротхузена об «исторической школе права в России» указанный тезис перенесен на единую государственную (или юридическую) школу Кавелина - Соловьева - Чичерина [17]. Опыт целостной реконструкции политических взглядов Чичерина дан в книге С. Бенсона [15], а сравнительная характеристика философских систем Гегеля и Чичерина - в книге П.М. Груичем [18, рр. 8-156]. Анализу непосредственно философии права Чичерина посвящена специальная глава в книге А. Валицкого [20, pp. 105164]. Последний оценивает его как наиболее последовательного представителя «классического либерализма на Востоке от Германии», стоящего «в одном ряду с самыми замечательными либералами XX века, включая Фридриха Хайека» [1, с. 29].

Сам Чичерин датировал рождение собственной философско-правовой концепции началом

\footnotetext{
${ }^{1}$ Согласно последнему, философская система Чичерина как по духу, так и по строению очень близка к докантовскому рационализму Декарта и Лейбница и совершенно далека от гегелевского, послекантовского сверхрационализма.

2 Особенно важными для нас являются: оценка первого («особенно сильное и оригинальное проявление гегелианство получило в философских трудах ... Б.Н. Чичерина») и наблюдение второго о том, что, оставаясь гегельянцем, Чичерин вносит в его методологию такие изменения, которые позволяют говорить о принципиальной формализации (аристотелизация Гегеля) и гносеологизации (отступление к позиции Канта) диалектики.
}

1850-х гг. Правда, с изложением ее в печати он выступил только в конце 1860-х гг. в «Истории политических учений», где и попытался «свести к некоторым общим, простым и ясным началам совокупность явлений человеческой истории, философии и права, и на этом основании вывести общий закон развития человечества» [12], а затем в конце 1870-х гг. - в «Науке и религии», а в критической форме (в полемике с Вл. Соловьевым) - в работе «Мистицизм в науке». В 1900 г. выходит «Философия права» как одно из основных сочинений Б.Н. Чичерина, ставшее также «заметным этапом в развитии философско-правовой мысли в России» и «образцом высокого уровня теоретичности и системности в рассмотрении материала» [11, с. 632].

Если сравнивать две «Философии права», Гегеля и Чичерина, разделенные во времени восемью десятилетиями, то, по мнению В.Н. Жукова, они предельно близки по структуре и по названию глав. Вместе с тем стоит заметить, что принципиальная ориентация Гегеля на триады заменяется «тетрадами», по крайней мере, в самых решающих пунктах, в чем проявилась не менее принципиальная мировоззренческая и методологическая позиция Чичерина [7]. Поэтому комплексы «Абстрактное право - Мораль Нравственность» Гегеля и «Личность и общество - Право - Нравственность - Человеческие союзы» Чичерина существенно различны.

Во-первых, у русского философа и теоретика права отсутствуют в единой связке нравственность и мораль. Во-вторых, праву предшествует общесоциологический очерк, правда, через призму личности (согласно Б.В. Емельянову, у Чичерина стыкуются нравственность и право, как выражение внутренней и внешней свободы человеческой личности [6, с. 64]). В-третьих, вместо трех общественных союзов - семьи, гражданского общества и государства, образующих у Гегеля три основные формы нравственного общежития, Чичерин вводит четвертый (церковь) и рассматривает их в иной исторической и смысловой последовательности (вряд ли прав Б.В. Емельянов, утверждавший, что, «как последователь Гегеля, Чичерин не выходит за рамки его схемы развития человеческой истории» [6, с. 84]). Чичерин, в-четвертых, ставит вслед за «государством» как общественным союзом «международные» (фактически - межгосударственные) отношения, тогда как «всемирная история» Гегеля вообще убирается из последней формы и переводится им в общий контекст учения об общественных союзах. 
На историческом аспекте и сосредоточим основное внимание. Нас будет интересовать вопрос о месте права в социальной структуре общества и системе обеспечения его функционирования и воспроизводства. Такая акцентировка позволяет увидеть, как нам представляется, два довольно неожиданных обстоятельства, показывающих очень любопытный характер взаимосвязи мысли Гегеля и Чичерина о праве в его философии.

Отправным пунктом возьмем позднюю самооценку Чичерина: «Чтение Гегеля убедило меня в истине исторического закона, состоящего в движении духа от единства к раздвоению и от раздвоения обратно к единству. Но я не мог примириться с построением Гегеля, который эпохою раздвоения считал Римскую империю и в христианстве видел начало высшего единства» [13, с. 88-89]. Спросим: а где же у Гегеля формулируется эта подвергаемая критике Чичерина позиция? Надо полагать, что в «Философии права», а специально, с разработкой деталей, - в «Философии истории». Проверим эту первую версию.

\section{Тема гражданского общества}

\section{в философии права Б.Н. Чичерина}

После Гегеля и Маркса гражданское общество обычно рассматривается в единой связке с государством, но между Гегелем и Чичериным по этому вопросу существует одно из самых серьезных расхождений. Используя термин «правовое состояние» для обозначения "римского мир» как третьей формы всемирно-исторического существования народов в «Философии истории» Гегеля, одновременно спроецируем его на «гражданское общество» Чичерина как частно-правовой общественный союз, исторически связываемый русским философом права с эпохой западно-европейского средневековья.

Начнем с Гегеля. Исходя из «Философии истории» сопоставим в характеристике Гегеля «правовое состояние» (римский мир) и «ось» истории (роль христианства) ${ }^{3}$. Факт христианства для Гегеля - один из самых значимых фактов всемирной истории: если восточный и античный миры, а тем более пять всемирно-исторических народов (Китай, Индия, Персия,

${ }^{3}$ Обратим внимание, что в разных курсах лекций (и в разных их изданиях) христианство помещалось во всемирной истории далеко не одинаковым образом оставляем здесь эту существеннейшую деталь для дальнейшего специального чисто философско-исторического анализа.
Греция, Рим) представлены как «частичные», то христианско-германский мир как раз и оказывается противопоставленным им всем своей целостностью, т.е. законченностью и завершенностью. И если бы Гегель в своих лекциях действительно настаивал на этом, доводя мысль об «оси» всемирной истории до ее концептуального выражения, как это ему приписывает К. Ясперс [14, с. 32], то пришлось бы принципиально выделять в истории не три или четыpe, а два основных периода: до Христа и после него 4 : «Германский дух есть дух нового мира, цель которого заключается в осуществлении абсолютной истины как бесконечного самоопределения свободы, той свободы, содержанием которой является сама ее абсолютная форма. Назначение германских народов состоит в том, чтобы быть носителями христианского принципа» [2, с. 361].

Вместе с тем в «Философии истории» и прямо говорится об исторической «оси» - в третьем отделе, посвященном, однако, императорскому периоду римской истории (во второй из глав, помещенной между общей характеристикой империи и кратким очерком о Византии и названной «Христианство»): «Бог познается как дух лишь таким образом, что он признается триединым. Этот новый принцип есть ось, вокруг которой вращается всемирная история. История идет до этого пункта и направляется отсюда далее. «Когда исполнилось время, бог послал своего сына», - сказано в Библии. Это означает не что иное, как-то, что самосознание возвысилось до таких моментов, которые принадлежат понятию духа, и до потребности понимать эти моменты как абсолютные» [2, c. 339-340].

Пытаясь понять это место в плане интересующего нас вопроса о феномене права и «гражданского общества», кратко прокомментируем его. Осевой пункт или осевая точка истории, по Гегелю, есть, выстраивая, так сказать, вертикаль между земным и небесным, приход в мир Бога, явление Абсолютного как субъективности, но божественной субъективности, т.е. Субъективности (Иисуса Христа, Сына Божьего). С другой стороны, в юридическом, чисто светском измерении, представляемом философским образом, римская «партикулярная субъективность» характеризуется Гегелем, скажем

\footnotetext{
${ }^{4}$ Так, например, следуя новозаветной христианской традиции, он и называет собственно христианскую эпоху во всемирной истории новым временем, новым миром.
} 
так, в горизонтальном, плоскостном обнаружении противоречивости-противоположности крайних пунктов устроения социальности следующим образом: «индивидуумы полагаются как атомы, но в то же время они подчинены суровой власти одного лица, которая, как monas monadum, есть власть над частными лицами. Следовательно, это частное право оказывается и небытием, непризнанием личности, и это состояние права есть совершенное бесправие. Это противоречие есть несчастье римского мира» [2, с. 339].

Итак, первое как бы надысторическое событие и связанная с ним событийная историческая субъективность, соотносится Гегелем с некоторым общим правилом, порядком, устройством римского мира, в котором утвердилась, именно как принцип империи, «доведенная до бесконечности конечность и партикулярная субъективность». Это соотнесение выражено словами: «благодаря тому же принципу субъективности родилось спасение мира; при этом оно родилось как этот единственный человек» [2, с. 339]. Иными словами, оба образа субъективности - светский и духовный, массовидный и неповторимо-единственный, чисто исторический и исторически-сверхисторический - представлены Гегелем в осевой точке истории, а хронологически - в эпохе римской империи.

Из этого следует: осевое время есть 1) время прихода Бога в мир, вхождения сверхистории в историю, соединения трансцендентного с имманентным, хотя и осуществляемое именно в формах исторических и имманентных (приход Бога в мир в человеческом обличье, как субъективности, т.е. как личности Иисуса Христа) и 2) время рождения христианской религии в качестве принципа для самой имманентно-исторической действительности, т.е. время замены римского духа более высоким христианским духом, но вырастающим из реального римского мира (римский дух, римский мир, императорская эпоха римской истории есть порождающее основание для христианства).

В этой двоякой (вертикально-горизонтально взаимосвязанной) двоякости осевого пункта истории и самой социально-гражданственной противоречивости римской исторической эпохи - ключ для гегелевского понимания всемирной истории. А также и римского права, и римского христианства - осевого фона и осевого центра исторического развития.

А что у Чичерина в этой связи? Вспомним еще раз о его несогласии с гегелевским «постро- ением», в котором он «эпохою раздвоения считал Римскую империю и в христианстве видел начало высшего единства». Первое, что бросается здесь в глаза, это неожиданное навязывание Гегелю такого понимания исторического развития через его «основной закон», как будто в «Философии истории» за эпохой единства следует эпоха раздвоения, приводящая к новому единству. Но ведь такой триады у Гегеля в его философском изображении всемирной истории просто нет, на что обратил внимание В.С. Соловьев в своей оценке «Философии истории» Гегеля. Она у него есть только история государства и права, а не общесоциальная и культурная история человечества), и при этом его четыре всемирно-исторических народа (или восточное, греческое, римское и германское «царства» «Философии права») изображаются на трех этапах исторического развития, включающего самостоятельные восточный, античный (без разделения на Грецию и Рим) и христианско-германский принципы (деспотия, республика и монархия) и соответствующие миры ${ }^{5}$.

Конечно, некоторая странность и особенность Рима (особенно в имперский период истории) в этой схеме налицо, но уж никак он не похож на вторую самостоятельную всемирно-историческую ступень раздвоения, без которой Чичерин не представлял себе действие основного исторического закона. Не похож, правда, с одной оговоркой: если не брать во внимание указанные выше моменты противоречия духовного и мирского, с одной стороны, и внутреннюю социально-государственную противоречивость граждан-атомов и гражданина-императора в юридически-мирском измерении. Точнее, если эту логически-диалектическую схематику вникновения Гегеля в существо римской эпохи не оторвать от исторически-правового и духовного компонентов римской действительности в виде некоторой идеальной модели, которую ничто не мешает перенести - без ее эмпирического сопровождения - в иную историческую среду.

А именно это и делает Чичерин, накладывая гегелевскую диалектико-логическую схему антагонизма (причем, в собственной жесткой и при этом плоскостной интерпретации) на европейские «средние века». Для этого, однако, пришлось построить самодовлеющее представление о «гражданском обществе»- не просто

5 О специфике различного рода периодизаций и классификаций хода (процесса) исторического развития у Гегеля см.: [10, с. 137-146]. 
как об одном из общественных союзов, но и как об элементе, заменившем древние формы государственности, не вышедшие еще за рамки «первоначальной слитности», подобно тому как и церковь обрела в средние века полную автономию. «Я увидел, - писал Чичерин в своих «Воспоминаниях», - что эпохою раздвоения следует признать не Римскую империю, а Средние века, где действительно являются два противоположных друг другу мира: с одной стороны, церковь, хранительница нравственного закона, с другой стороны, светская область, в которой господствовало частное право» [13, с. 88-89].

Итак, философия права у Чичерина (как философия истории) существенно иная, чем у Гегеля. Но сама идея противоречия (как антагонизма) - идея чисто гегелевская, правда, в метафизическом и методологическом смыслах. Возникает вопрос: есть ли в этой идее и нечто от философии права в собственном значении? При такой постановке вопроса мы и обнаруживаем возможность увидеть все же чисто гегелевские истоки диалектико-исторического воззрения на право, но уже не в «Философии истории», а в «Феноменологии духа».

\section{Тема «отчужденного духа»}

\section{в философии права Б.Н. Чичерина}

Вспомним, что именно в «Феноменологии духа» будущая философия права Гегеля (как и его философия истории) совпадает с философией духа, изложенной в шестом разделе «Феноменологии», предшествующем разделу «Религия». Но сначала - об «отчужденном духе», представляемом, правда, в «Феноменологии» еще и как «образованность» (об этом см.: [9]).

Двойственное чувство возникает всякий раз, когда, читая «Феноменологию духа» [3], снова и снова наталкиваешься на странное, но при этом, если быть внимательным, весьма любопытное обстоятельство: Bildung Гегеля передается в переводе Г.Г. Шпета то как «образование», то как «образованность». Причем речь идет не о той двойственности термина, которая в силу его явной полисемантичности непрерывно заявляет о себе в любой точке текста ${ }^{6}$,

${ }^{6}$ То как явная соотнесенность процесса образования и его результата (или полного, завершенного или же на какой-то из предварительных ступеней развития), то как принципиальное двуединство мирового образовательного процесса в целом (объективного хода развития духовной субстанции к своему итоговому результату) и повторяющего это движение образования-формирования индивида. но о некой двойственности в отношении образовательных результатов - целостной системы образования или же ее отдельных структурных или составных элементов в виде единичных образований или формообразований духа.

Следовательно, в переводе Шпета зафиксирован какой-то очень важный разделительный знак между образованием и образованностью, на немецком терминологическом языке Гегеля не получивший ясного и отчетливого выражения. Второе - это историческая действительность, передаваемая термином «образованность», которая большинством исследователей и интерпретаторов «Феноменологии» почему-то упорно связывается с эпохой Просвещения и подготовкой Французской революции ${ }^{7}$.

Но для нас самый интересный вопрос, практически никем не поставленный, заключается в следующем: почему именно образованность, а не право ставится Гегелем между нравственностью и моральностью в качестве основного опосредствующего звена? Странность, неожиданность, если не парадоксальность заключается в том, что, как общеизвестно, в сложившейся системе Гегеля, например, в «Философии права» это место в триадической схеме основных объективно-практических духовных образований (в соответствии с чем и сама работа разделяется на три основные части) занимает «абстрактное право» [4, с. 96]. В «Философии истории» показано, как дух сумел «развиться до ... формы абстрактной всеобщности», что и произошло в Риме (с его «абстрактным государством, политикой и властью»), который (Рим), «в противоположность этой всеобщности, создает личность (вместо нравственной индивидуальности), являющуюся «основным определением права» [2, c. 303]. Наконец, и в самой «Феноменологии», по Гегелю, «нравственность» первоначально, на переходном отрезке от «истинного духа» к «отчужденному духу» (на этапе кризиса полиса и формирования эллинистических монархий греко-македонских предшественниц имперского Рима - прим.авт.) «пропадает в формальной всеобщности права» [3, с. 235]. Причем краткая гегелевская характеристика «правового состояния» [3, с. 256-260] вполне созвучна с его более поздними характеристиками.

Представляя (в главе «Дух») ход развития субстанции, становящейся субъектом (в этом ее

\footnotetext{
${ }^{7}$ Например, в работах А.В. Гулыги, Н.В. Мотрошиловой, Е.Б. Рашковского. Правда, есть и иное толкование - в знаменитых лекциях о «Феноменологии» А. Кожева и в книге В.А. Погосяна.
} 
двуединстве Гегель находил принципиальную ее характеристику и определенность), как исторический процесс, философ обратил внимание на факт, практически не привлекший внимания исследователей. А именно: на своеобразную составленность единой истории субстанциального развития из двух самостоятельных эмпирических историй: 1) классической эллинской цивилизации, нашедшей свое завершение уже в условиях имперского Рима и 2) варварских германских народов, ставших завоевателями и наследниками этой империи. Момент христианства в этой исторической картине включен в общий исторический контекст (в «Философии истории» он будет выделен в третий самостоятельный элемент предстоящей в первые века нашей эры «стыковки» в целостность мирового исторического развития, уже перешедшего на европейскую почву, на его последнем, христианско-германском этапе). В общий - и потому, что он касается первой (классической эллинской и римской) эпохи, и потому, что оказывается начальной формой «образования» из германских варваров эпохи «великого переселения народов» цивилизованных народов эпохи европейского средневековья.

Одновременно с этой исторической схемой-моделью у Гегеля присутствует и собственно диалектическое понимание развития исторического процесса на почве европейской цивилизации (а быть может - и мировой истории). Имеется в виду его общая периодизация развития субстанциального процесса. Дух (в последующей терминологии - «объективный дух»), согласно Гегелю, проходит три ступени развития: 1) «истинный дух» (нравственность), 2) «отчужденный от себя дух» (образованность), 3) «Дух, обладающий достоверностью себя самого» (моральность) [3, с. 234-443].

Отчужденный дух в локально-европейском осмыслении исторического процесса предстает как классическая образованность и христианская образованность, стыкуемые с «невежеством» варваров, что каким-то образом позволяет упаковать в целостность два разных цивилизационных потока истории: 1) язычески-варварский, ставший язычески-классическим у греков и римлян (благодаря, прежде всего, праву и философии) и 2) язычески-варварский (у германцев), которому еще только представилась возможность обретения культурной формы - сначала через наполнение смыслом христианской формы образованности, а затем и приобщения к классике, а тем самым - возвращения ей (вместе с правом и философией, свободой и разумом) наличного бытия в культуре.

А теперь - о Чичерине. Интересующий нас вопрос о влиянии философии истории Гегеля, представленной в «Феноменологии духа», и самого этого произведения на философско-исторические построения Б.Н. Чичерина, насколько мы можем судить сегодня, практически не рассматривался. Что же мы можем сказать по этому вопросу?

Момент первый. Чичерин, вспоминая об освоении гегелевского наследия, отмечал: «Вслед за философией истории он в течение нескольких месяцев изучал историю философии, а затем - логику и, наконец, засел за феноменологию и энциклопедию» [13, с. 73-74]. По вопросу о том, в какой мере это привело к оформлению философии религии, права и философско-исторических взглядов русского мыслителя, имеется свидетельство, сохранившееся в чичеринском «Дневнике» за 1851 г.

За двадцать восемь лет до написания «Науки и религии» и за полвека до «Философии права» Чичерин так изложил в дневнике существо основного закона духовного исторического развития человечества: 1) «Философия и религия одно и то же: религия есть воззрение на мир в форме постоянной и неизменной, философия в форме движущейся и изменяемой; религия есть человеческое мышление, установившееся в прочной системе, составляющей основу жизни целой эпохи, философия есть движение ума от одной религии к другой через ряд ступеней, составляющих особенную скоропреходящую систему» ${ }^{8}$; 2) «Поэтому религий может быть только три, хотя каждая имеет множество видоизменений: язычество, начиная от восточного пантеизма до греко-римского национального антропоморфизма, Христианство, которое как религия человечества собственно одно, ибо многочисленные секты, возникшие в новое время, суть признаки извращения и упадка,

${ }^{8}$ И по общему смыслу, и в повторах-совпадениях отдельных терминов и характеристик («постоянная» и «неизменная» форма «Религии» у Чичерина в соотнесенности со «спокойным» и «устойчивым» мышлением гегелевской «Веры»; «движущаяся» и «изменяемая» форма «Философии» - в соотнесенности с «исчезанием» и «негативным движением» того философствования, которое характерно для «Здравомыслия») перед нами два фрагмента, явно связанных и по форме, и по содержанию, допускающих прямое сближение ходов и способов мысли Гегеля и Чичерина. Это - явная «привязка» к «Феноменологии духа». 
наконец та религия, основанная на новой науке, которая установится в будущем, и составит предел человеческого развития» (Чичерин Б.Н. Дневник, 27 апреля - 21 октября 1851 г.; 14 апреля - лето 1856 г. ОР РГБ. Ф.334. К. 17. Ед. хр. 5.11. Л. 2об.).

По Чичерину, если исходить из верховного критерия философии религии, в рамках которой у него размещается философия права, первая ступень всемирной истории - развитие натуралистических религий, что и составляет так называемый «первый синтетический период, или период первоначального единства» (в своей высшей форме это эпоха великих цивилизаций Востока). Вторая ступень - христианство, представляющее «второй синтетический период, или период раздвоения» (это - европейское Средневековье). Наконец, третья ступень должна быть представлена в дальнейшем универсальной религией будущего (религией духа).

Формой перехода от первой ступени ко второй, т.е. формой разложения первоначальной слитности натуралистических религий и социальной общности, выступает в теории развитие греческой философии, а на практике - римского права и государства, составляющих содержание «первого аналитического периода» в истории человечества. В этой же роли, на переходе от второй ступени к третьей, выступает новоевропейская философия и государственно-правовые режимы эпохи централизации и абсолютизма, образующие «второй аналитический период». Синонимом раздвоенности средневековой промежуточной ступени на противоположности служит у Чичерина распадение христианского мира в средние века на церковь восточную и церковь западную, а в самом западном средневековом обществе - гражданского быта (государства здесь нет) и церкви.

Но подведем итоги. Отправная точка рассмотрения философско-правовой концепции Б.Н. Чичерина через призму «Феноменологии духа» - понятие «Bildung» у Гегеля, представляющее не только его концепцию «образования» в обычном смысле, но и (в виде «образованности») - взгляд на мир греко-римской культуры и социальности (до и после завоевания Римской империи германцами-варварами), что сразу же историзирует Bildung и показывает его в виде напряженного противоречия (диалектика «отчужденного духа») и, наконец, Bildung вместе с «правом» и «Революцией» - с двух исторических концов, его обрамляющих, - входящее у Гегеля и в историческое, и в системное взаимо- отношение и единство с «Нравственностью» и «Моралью», историзируется у Чичерина существенно иначе.

Здесь важно второе наблюдение - предпочтение гегельянцем Б.Н. Чичериным не той периодизации мировой истории, которая дана в «Философии истории» (с четырьмя известными формами: Восток - Греция - Рим - Германский мир), но «феноменологической»- с «отчужденным духом» в центре европейской (и лишь потенциально, в использовании Чичериным, мировой) истории. Если во второй периодизации отчужденный дух (эпоха религии и образованности) был обрамлен у Гегеля нравственностью и моралью (от реально-субстанциальной греческой полисности до мыслительного «немецкого моралитета» конца XVIII - начала XIX вв. и располагалась гигантская по длительности полоса действия «отчужденного духа» с прелом выражения именно в средние века), то в чичеринской мировой интерпретации, во-первых, не осталось места для морали как всемирно-исторического образования, а место нравственности, во-вторых, по большому счету, заняла религия первого «синтетического» периода (первобытности и Востока) - со скромной аналитической добавкой из греческой философии и римского права. Последнее и перекочевало у Чичерина в средние века в форме частно-правового гражданского быта или гражданского общества.

\section{СПИСОК ЛИТЕРАТУРЫ}

1. Валицкий А. Нравственность и право в теориях русских либералов конца XIX - начала ХX вв. // Вопросы философии. 1991. № 12. C. 25-39.

2. Гегель Г.В.Ф. Лекции по философии истории. СПб.: Наука, 1993.

3. Гегель Г.В.Ф. Система наук. Ч. 1. Феноменология духа. СПб.: Наука, 2006.

4. Гегель Г.В.Ф. Философия права. М.: Мысль, 1990.

5. Дидык М.А. Феномен права и ось истории в философии культуры Гегеля // Философия права. 2007. № 4. С. 134-138.

6. Емельянов Б.В. Борис Чичерин: Интеллектуальная биография и политическая философия. Екатеринбург: Изд-во Урал, ун-та, 2003.

7. Ерыгин А.Н. Традиционная и модернизирующаяся Россия в философии истории русского либерализма (К.Д. Кавелин, С.М. Соловьев, Б.Н. Чичерин): Ч. 1. Философия истории русского либерализма второй половины XIX в. 
(тема России). Ростов-на-Дону: Изд-во Рост. ун-та, 2004.

8. Ерыгин А.Н. Феномен права, отчуждения и образованности в истории (Б.Н. Чичерин и «Феноменология духа» Гегеля) // Философия права. 2008. № 4. С. 14-18.

9. Ерыгин А.Н. «Феноменология духа» Гегеля и философия истории в России (И.В. Киреевский и Б.Н. Чичерин) // «Феноменология духа» Гегеля в контексте современного гегелеведения / Отв. ред. Н.В. Мотрошилова. М.: Канон; РООИ «Реабилитация», 2010. С. 550-567.

10. Ерыгин А.Н. Вокруг «Феноменологии духа» Гегеля: тема сознания и истории (19732013 гг.). Ростов-на-Дону: Изд-во ЮФУ, 2016.

11. Жуков В.Н. Философия права // Русская философия: Энциклопедия. М.: Алгоритм, 2007.

12. Чичерин Б.Н. История политических учений: В 5 ч. Ч. 1. М., 1869.

13. Чичерин Б.Н. Воспоминания. Москва сороковых годов. М.: Издание М. и С. Сабашниковых, 1929.

14. Ясперс К. Смысл и назначение истории. М.: Республика, 1994.

15. Benson, S., 1975. The conservative liberalism of Boris Chicherin. Forschungen zur osteuropaischen Geschichte, no. 21, pp. 17-114.

16. Fitzsimons, M.A., Pundt, A.G. and Nowell, Ch.E. eds., 1954. The development of historiography. Harrisburg.

17. Grothusen, K.-D., 1962. Die Historische Rechtsschule Russlands. Ein Beitrag zur russischen Geistesgeschichte in der zweiten Halfte des 19. Jahrhunderts. Giessen.

18. Grujic, P.M., 1985. Cicerin, Plechanov und Lenin. Studien zur Geschichte des Hegelianismus in Russland. Munchen, 1985.

19. Mazour, A.G., 1958. Modern Russian historiography. Princeton.

20. Walicki, A., 1987. Legal philosophies of Russian liberalism. Oxford: Oxford University Press.

\section{REFERENCES}

1. Walicki, A., 1991. Nravstvennost' i pravo v teoriyakh russkikh liberalov kontsa XIX - nachala XX vv. [Morality and law in the theories of Russian liberals, late XIXth - early XXth century], Voprosi filosofii, no. 12, pp. 25-39. (in Russ.)

2. Hegel, G.W.F., 1993. Lektsii po filosofii istorii [Lectures on the philosophy of history]. Sankt-Peterburg: Nauka. (in Russ.).

3. Hegel, G.W.F., 2006. Sistema nauk. Ch. 1. Fenomenologiya dukha [The system of sciences.
Part 1. The phenomenology of spirit]. SanktPeterburg: Nauka. (in Russ.).

4. Gegel, G.W.F., 1990. Filosofiya prava [Philosophy of law]. Moskva: Mysl'. (in Russ.).

5. Didyk, M.A., 2007. Fenomen prava i os' istorii $\mathrm{v}$ filosofii kul'tury Gegelya [The phenomenon of law and the axis of history in Hegel's philosophy of culture], Filosofiya prava, no. 4, pp. 134-138. (in Russ.).

6. Emel'yanov, B.V., 2003. Boris Chicherin: Intellektual'naya biografiya i politicheskaya filosofiya [Boris Chicherin: Intellectual biography and political philosophy]. Ekaterinburg: Izd-vo Ural. un-ta. (in Russ.).

7. Erygin, A.N., 2004. Traditsionnaya i moderniziruyushchayasya Rossiya $\mathrm{V}$ filosofii istorii russkogo liberalizma (K.D. Kavelin, S.M. Solovyov, B.N. Chicherin): Ch. 1. Filosofiya istorii russkogo liberalizma vtoroi poloviny XIX veka (tema Rossii) [Traditional and modernizing Russia in the philosophy of history of Russian liberalism (K.D. Kavelin, S.M. Solovyov, B.N. Chicherin): Part 1. Philosophy pf history of Russian liberals in the late XIXth century]. Rostov-na-Donu: Izd-vo YuFU. (in Russ.).

8. Erygin, A.N., 2008. Fenomen prava, otchuzhdeniya i obrazovannosti V istorii (B.N. Chicherin i «Fenomenologiya dukha» Gegelya) [The phenomenon of law, alienation and education in history (B.N. Chicherin and Hegel's «The phenomenology of spirit»)], Filosofiya prava, no. 4, pp. 14-18. (in Russ.).

9. Erygin, A.N., 2010. «Fenomenologiya dukha» Gegelya i filosofiya istorii V Rossii (I.V. Kireevskiy i B.N. Chicherin) [Hegel's «The phenomenology of spirit» and philosophy of history in Russia (I.V. Kireevskiy and B.N. Chicherin)]. In: Motroshilova, N.V. ed., 2010. «Fenomenologiya dukkha» Gegelya v kontekste sovremennogo gegelevedeniya. Moskva: Kanon; ROOI «Reabilitatsiya», pp. 550-567. (in Russ.)

10. Erygin, A.N., 2016. Vokrug «Fenomenologii dukha» Gegelya: tema soznaniya i istorii (19732013 gg.). [Around Hegel's «The phenomenology of spirit»: the issues of consciousness and history]. Rostov-na-Donu: Izd-vo YuFU. (in Russ.)

11. Zhukov, V.N., 2007. Filosofiya prava [Philosophy of law]. In: Russkaya filosofiya: Entsiklopediya. Moskva: Algoritm. (in Russ.)

12. Chicherin, B.N., 1869. Istoriya politicheskikh uchenii: v 5 ch. Ch. 1 [History of political doctrines in 5 parts. Part 1]. Moskva. (in Russ.).

13. Chicherin, B.N., 1929. Vospominaniya. Moskva sorokovykh godov [Memories. Moscow 
of the fortieth]. Moskva: Izdanie M. i S. Sabashnikovykh. (in Russ.).

14. Jaspers, K., 1994. Smysl i naznachenie istorii [The origin and goal of history]. Moskva: Respublika. (in Russ.).

15. Benson, S., 1975. The conservative liberalism of Boris Chicherin. Forschungen zur osteuropaischen Geschichte, no. 21, pp. 17-114.

16. Fitzsimons, M.A., Pundt, A.G. and Nowell, Ch.E. eds., 1954. The development of historiography. Harrisburg.
17. Grothusen, K.-D., 1962. Die Historische Rechtsschule Russlands. Ein Beitrag zur russischen Geistesgeschichte in der zweiten Halfte des 19. Jahrhunderts. Giessen.

18. Grujic, P.M., 1985. Cicerin, Plechanov und Lenin. Studien zur Geschichte des Hegelianismus in Russland. Munchen, 1985.

19. Mazour, A.G., 1958. Modern Russian historiography. Princeton.

20. Walicki, A., 1987. Legal philosophies of Russian liberalism. Oxford: Oxford University Press.

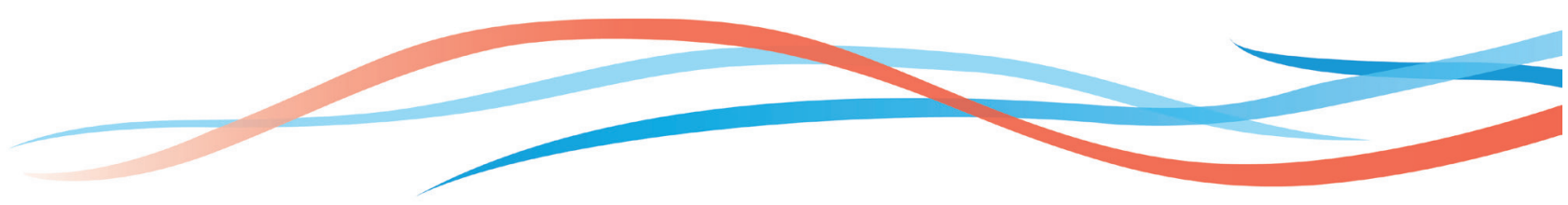

